\title{
OPEN
}

\section{Author Correction: A genomic catalog of Earth's microbiomes}

Stephen Nayfach, Simon Roux, Rekha Seshadri, Daniel Udwary (D), Neha Varghese, Frederik Schulz (D), Dongying Wu, David Paez-Espino (D), I-Min Chen (D), Marcel Huntemann (D), Krishna Palaniappan, Joshua Ladau, Supratim Mukherjee (iD, T. B. K. Reddy (D), Torben Nielsen, Edward Kirton, José P. Faria, Janaka N. Edirisinghe, Christopher S. Henry, Sean P. Jungbluth, Dylan Chivian (D), Paramvir Dehal, Elisha M. Wood-Charlson D, Adam P. Arkin, Susannah G. Tringe (D), Axel Visel (D), IMG/M Data Consortium*, Tanja Woyke (D), Nigel J. Mouncey (D), Natalia N. Ivanova (D), Nikos C. Kyrpides (D) and Emiley A. Eloe-Fadrosh (iD

Correction to: Nature Biotechnology https://doi.org/10.1038/s41587-020-0718-6, published online 9 November 2020.

In the version of this article initially published, four people were missing from the alphabetical list of IMG/M Data Consortium members: Lauren V. Alteio of the Centre for Microbiology and Environmental Systems Science, University of Vienna, Vienna, Austria; Jeffrey L. Blanchard of the Biology Department, University of Massachusetts Amherst, Amherst, MA, USA; Kristen M. DeAngelis of the Department of Microbiology, University of Massachusetts Amherst, Amherst, MA, USA; and William Rodriguez-Reillo of the Research Computing Division, Harvard Medical School, Boston, MA, USA. The error has been corrected in the PDF and HTML versions of the article.

${ }^{\star}$ A list of authors and their affiliations appears online.

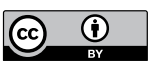

Open Access This article is licensed under a Creative Commons Attribution 4.0 International License, which permits use, sharing, adaptation, distribution and reproduction in any medium or format, as long as you give appropriate credit to the original author(s) and the source, provide a link to the Creative Commons license, and indicate if changes were made. The images or other third party material in this article are included in the article's Creative Commons license, unless indicated otherwise in a credit line to the material. If material is not included in the article's Creative Commons license and your intended use is not permitted by statutory regulation or exceeds the permitted use, you will need to obtain permission directly from the copyright holder. To view a copy of this license, visit http://creativecommons.org/ licenses/by/4.0\%.

Published online: 1 April 2021

https://doi.org/10.1038/s41587-021-00898-4

() The Author(s) 2021 